\title{
Prediction of hydrogen flame propagation in a channel with exit contraction
}

\author{
Ali Cemal Benim*, and Björn Pfeiffelmann \\ Center of Flow Simulation (CFS), Department of Mechanical and Process Engineering, Düsseldorf University of Applied Sciences, \\ Münsterstr. 156, D-40476 Düsseldorf, Germany
}

\begin{abstract}
The propagation of a flame front in a homogeneous and initially quiescent hydrogen-air mixture in a channel with exit contraction is numerically analyzed by means of Computational Fluid Dynamics. For the given configuration, the compressibility effects are important, the average pressure increases in time due to the exit contraction, and pressure waves occur, which affect the flame propagation. Flow turbulence is modelled by the Realizable $\mathrm{k}-\varepsilon$ model. In modelling combustion, turbulence-chemistry interactions are neglected. Predictions are compared with the measurements for evolution of the flame shape, propagation speed and pressure. It is observed that the flame propagation speed, and, thus, the rate of pressure increase are over-predicted by the present approach. Still, a fair qualitative agreement to measurements is observed.
\end{abstract}

\section{Introduction}

Power generation by thermal machinery largely depends on the combustion process. As the efforts for exploiting renewable energies, as well as recovery methods [1] increase, combustion remains as an important energy conversion method.

Combustion of hydrogen containing fuels plays an important role in clean energy supply. Hydrogen offers an attractive method to store excess renewable energies [2]. Further, instead of combustion [3], gasification represents an attractive alternative for utilization of solid fuels [4]. The gasification product contains a remarkable percentage in hydrogen. There is also a growing interest in hydrogen production by nuclear energy [5].

Hydrogen has very different material properties compared to other gases and can change the properties of the mixture when added to the mixture even in small amounts.

Thus, use of hydrogen containing fuels is a great challenge. In premixed combustion, a principal problem is flashback [6-9]. Hydrogen addition to the burnable gas increases its flashback propensity remarkably due to high reactivity of hydrogen.

Safety, in general, is an important issue in relationship with the usage of hydrogen $[10,11]$. The wider flammability range, greater propensity to leak than other common gaseous fuels, low activation energy, etc. make it easier to cause accidental fires, detonations and asphyxiations.

Thus, the safety practices in production, storage, distribution and use of hydrogen are key issues to industrial hydrogen energy utilization [12], as the safety standards that are commonly applied to the systems with small amounts of hydrogen or hydrocarbons may not work when applied to larger amounts of hydrogen $[13,14]$.

Although hydrogen is currently distributed mainly by trucks with steel cylinders, transport by pipelines is increasingly emerging as an alternative for a comprehensive and largescale use of hydrogen. Therefore, the investigation of the burning behavior of hydrogen air mixtures in tubes and channels is necessary from the safety standpoint.

Many experimental, computational and theoretical studies on premixed flame propagation in closed and semi-closed tubes have already been carried out [14-18]. Still, there is need for further investigations of different aspects of the phenomenon, including the details of the computational modelling. This is the scope of the present contribution.

\section{Problem formulation}

The measurements of Xiao et al. [15] are taken as the test case. The combustion system is a partially-open duct $82 \mathrm{~mm}$ square by $530 \mathrm{~mm}$ long. There is a circular opening placed on the upper wall near the right end of the duct.

The duct is filled with a premixed mixture of hydrogen and dry air with a hydrogen volume fraction of $30 \%$. The temperature and pressure of the gas prior to ignition are $298 \mathrm{~K}$ and $101325 \mathrm{~Pa}$, respectively. The flame is ignited by a spark. Flame propagation is measured by optical means. Pressure is measured by a transducer. Measurements were performed for different opening ratios. The opening ratio is the ratio of open area to the area of the duct cross section. In the present study, an opening ratio of 0.187 is considered.

\footnotetext{
* Corresponding author: alicemal@prof-benim.com
} 


\section{Models}

The simulations are performed using the CFD code ANSYS Fluent 18.0 [19]. Differential balance equations of mass, momentum, energy, species mass fractions, as well as turbulence quantities are solved for the chemically reacting mixture, assuming an ideal gas behavior [20,21]. Buoyancy is neglected. The radiative heat transfer [22] is also omitted.

The temperature dependence of specific heat capacities are modelled by a pair of fourth order polynomials [23], for low and high temperature ranges. Transport properties are calculated by the kinetic theory and the mixture properties by mixing laws [19-21,24,25].

Modelling turbulence in the current case is not an easy matter. Initially, with low velocities, turbulence may not be expected. Turbulence may occur at late stages with increasing velocities. A Large Eddy Simulation (LES) approach [26-28] would be convenient for the present case, but it is not currently applied due to its very high computational costs. Presently, a URANS (Unsteady Reynolds Averaged Numerical Simulation) approach is applied [29], the accuracy of which, is to be assessed by comparisons with the experiments. A turbulent viscosity based, two-equation turbulence model, namely the Realizable k- $\varepsilon$ model $[19,29,30]$ (k: turbulence kinetic energy, $\varepsilon$ : dissipation rate of k) is used as the turbulence model.

As combustion mechanism, the detailed mechanism of Conaire et al. [31] is used. In calculating the reaction rates via Arrhenius rate expressions [20], the effect of turbulence fluctuations is neglected. Although the present "no-model" approach is cannot be seen to be accurate, it is found to provide an acceptable initial approach for the present case.

A coupled solver [19] is used. To convective terms, a second-order upwind scheme [19] is applied. Time discretization is performed by a Bounded Second Order Implicit scheme [19].

\section{Results}

The geometry is approximated as $2 \mathrm{D}$ axisymmetric. The outlet area is approximated as a circumferential opening with the same opening ratio. A sketch of the modelled solution domain is presented in Figure 1.

At the outlet, the static pressure is prescribed. At the walls, no-slip conditions apply. Initially, a quiescent, atmospheric mixture of hydrogen and air is prescribed. For turbulence quantities, vanishingly small initial quantities are prescribed. Ignition is accomplished by prescribing temperature and species mass fractions within a tiny sub-domain ("spark" in Figure 1).

An equidistant grid consisting of square shaped volumes with the size of $0.5 \mathrm{~mm}$ is used as the "base grid". This resolution by $0.5 \mathrm{~mm} \times 0.5 \mathrm{~mm}$ cells has been borrowed from the previous study of Xiao et al. [15] on a very similar problem. Based on this "base grid" non-conformal local grid refinements are applied to achieve sufficiently fine grid resolution of the flame front.

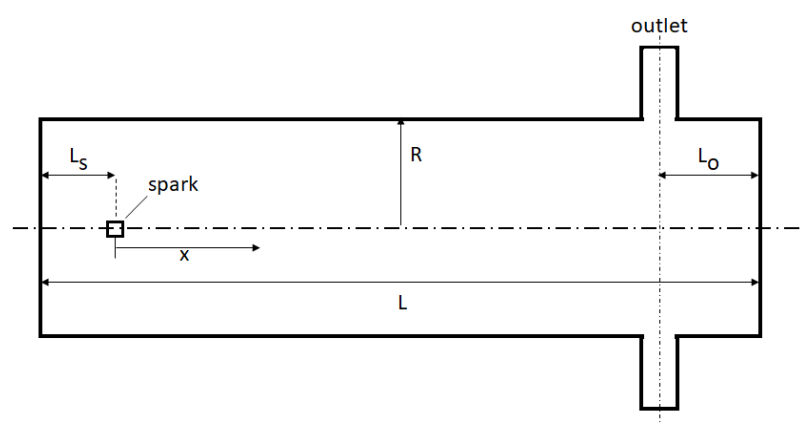

Figure 1. Solution domain

$(\mathrm{L}=530 \mathrm{~mm}, \mathrm{Ls}=55 \mathrm{~mm}, \mathrm{Lo}=75 \mathrm{~mm}, \mathrm{R}=41 \mathrm{~mm})$

Predicted field distributions of the static pressure (gauge pressure, $\Delta \mathrm{p}=\mathrm{p}-\mathrm{p}_{\text {outlet}}$ ) at initial instants, shortly after ignition are displayed in the contour plots (as detail plots) in Figure 2. Pressure (acoustic) waves generated by the ignition and their reflection by the combustor walls and interaction can be observed in Figure 2.

The predicted field distributions of the velocity magnitude at four instants of time after ignition are presented in Figure 3, as detail plots.

One can see, how the flame front expands in time, and how the gas is accelerated in front of the rapidly expanding flame front.

At the same time, it can also be observed that the initially $(\mathrm{t}=1.0 \mathrm{~ms})$ spherical shape of the flame front gradually evolves to the shape of an ellipsoid. This is expectedly mainly due to the effect of the confining walls of the combustor.

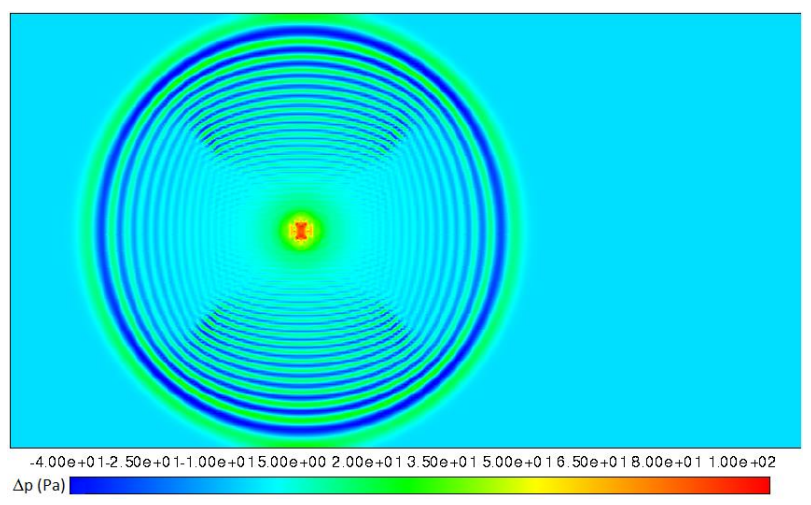

(a)

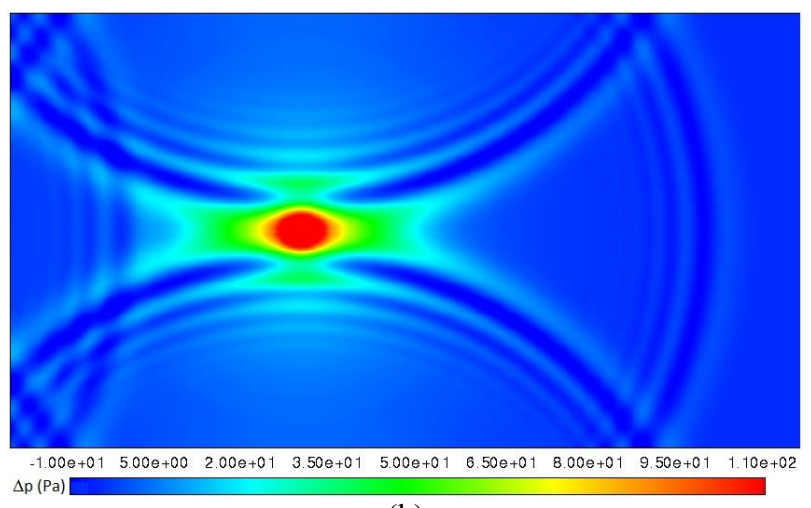

(b)

Figure 2. Predicted fields of gauge pressure at initial instants after ignition (detail), (a) $\mathrm{t}=0.1 \mathrm{~ms}$, (b) $\mathrm{t}=0.2 \mathrm{~ms}$ 

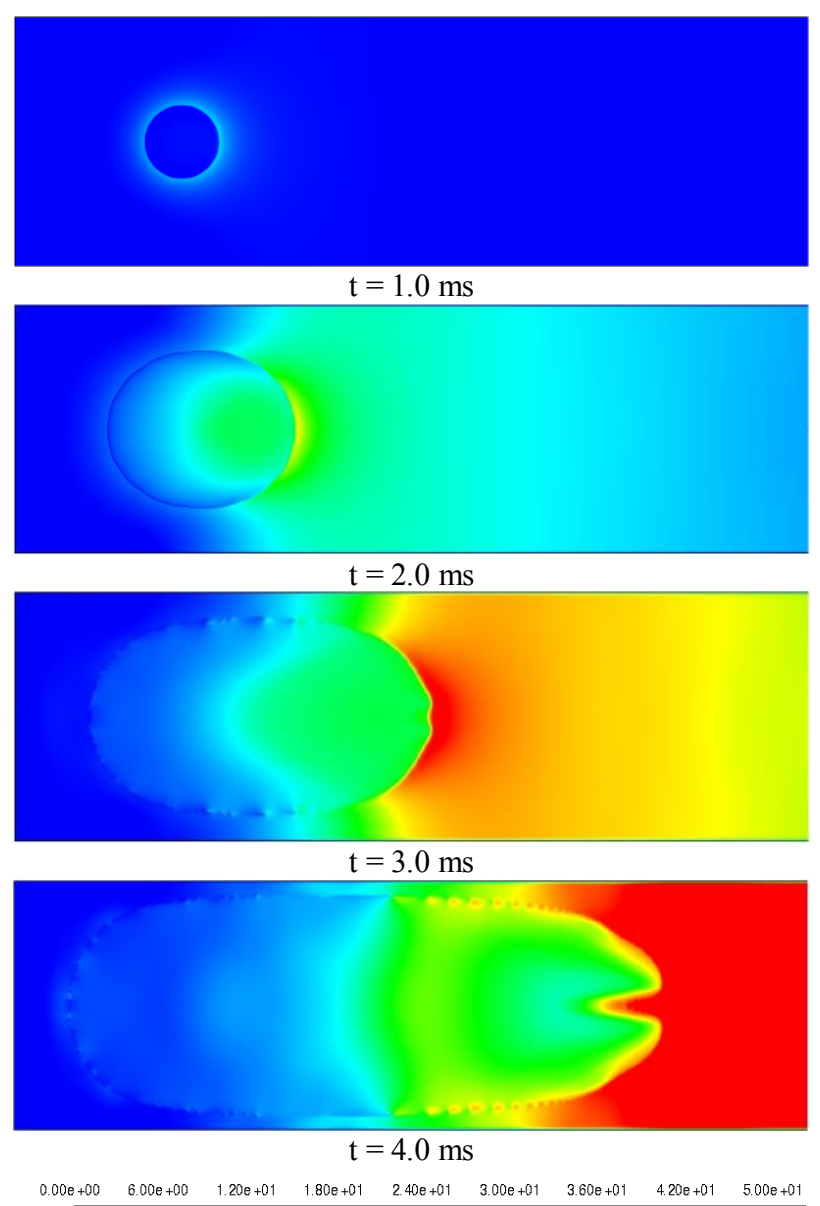

$\begin{array}{rllllllll}0.00 e+00 & 6.00 e+00 & 1.20 e+01 & 1.80 e+01 & 2.40 e+01 & 3.00 e+01 & 3.60 e+01 & 4.20 e+01 & 5.00 e+01 \\ V(m / s) & & & & & & & & \end{array}$

Figure 3. Predicted fields of velocity magnitude at different instants of time after ignition (detail)

The predicted field distributions of the static temperature at four instants of time $(\mathrm{t}=1.0,2.0,3.0,4.0 \mathrm{~ms})$ after ignition are presented in Figure 4 , as detail plots. The evolution of the shape of the flame front in time, from sphere to ellipsoid, can even more clearly be observed in Figure 4. It is interesting to note that a "notch" or "v" like shape gets formed on the right side of the flame expanding towards the outlet.

The predicted location of the flame leading tip (measured from the spark position) as well as the evolution of the static pressure at the position of the pressure transducer $(7.5 \mathrm{~cm}$ away from the right wall) are compared with the experiments in Figure 5 and Figure 6.

It can be observed in Figure 5 that the change of the flame tip position shows a nearly linear dependence on time, for the considered period of time, which is indicated by measurements and predictions, both. The predictions show a good qualitative agreement with the measurements. Quantitatively, the predicted position of the flame tip is slightly ahead of the measured position of the flame tip for the whole considered time range, which indicates a continuous overprediction of the flame propagation speed.

In Figure 6, it can be seen that the pressure at the measuring point remains constant for the first two milliseconds. Then, a continuous increase of pressure is

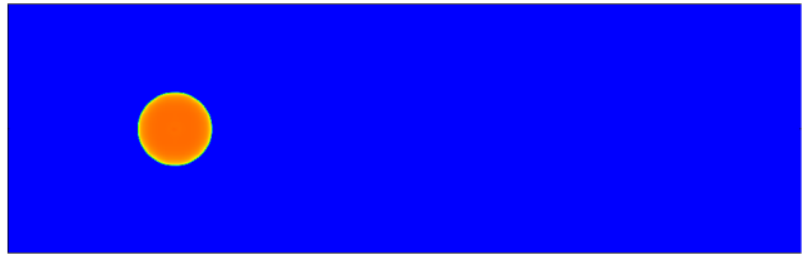

$\mathrm{t}=1.0 \mathrm{~ms}$

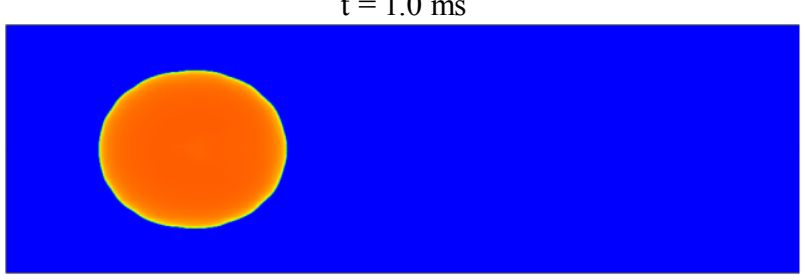

$\mathrm{t}=2.0 \mathrm{~ms}$

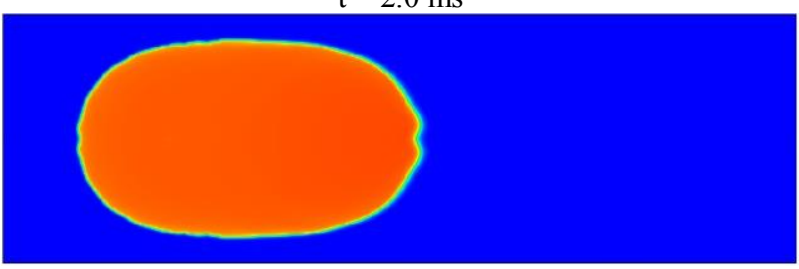

$\mathrm{t}=3.0 \mathrm{~ms}$

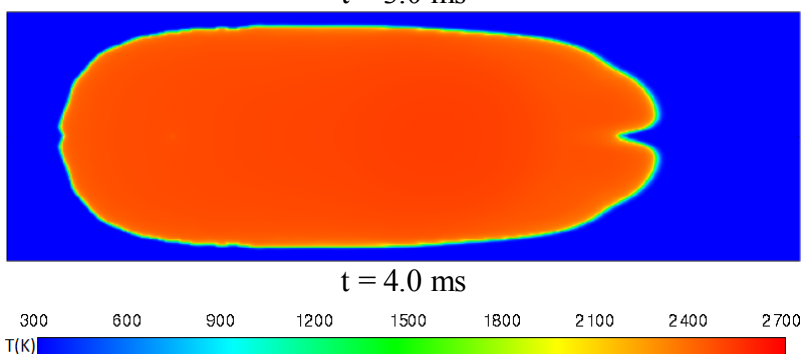

Figure 4. Predicted fields of static temperature at different instants of time after ignition (detail).

measured. The calculations predict the measured qualitatively well. Quantitatively, an overprediction is, again, observed, which is compatible with the previous finding (Fig. 5).

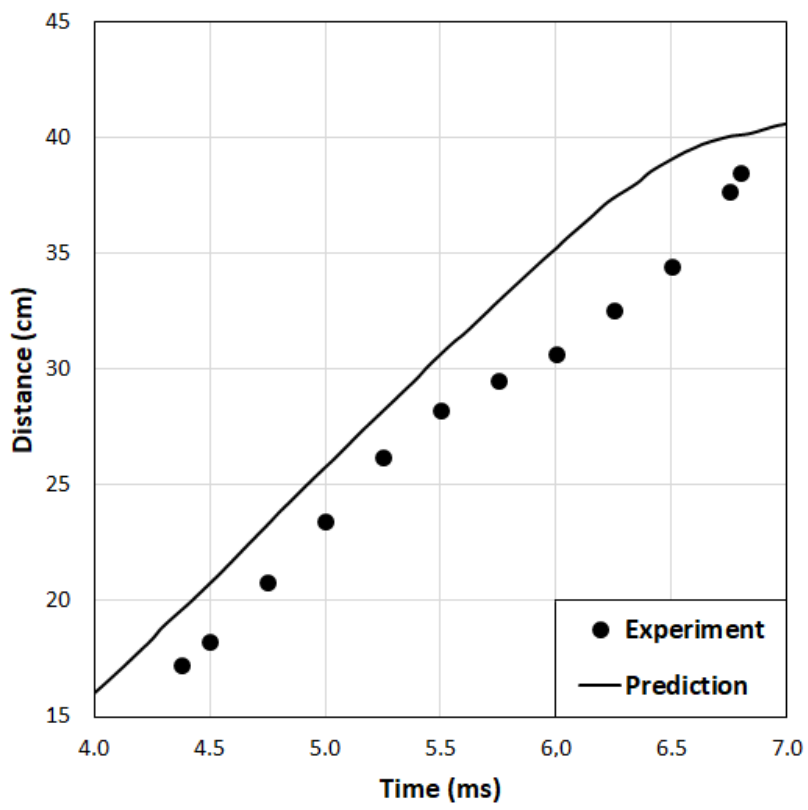

Figure 5. Location of flame leading tip as function of time, present predictions vs. experiments [15] 


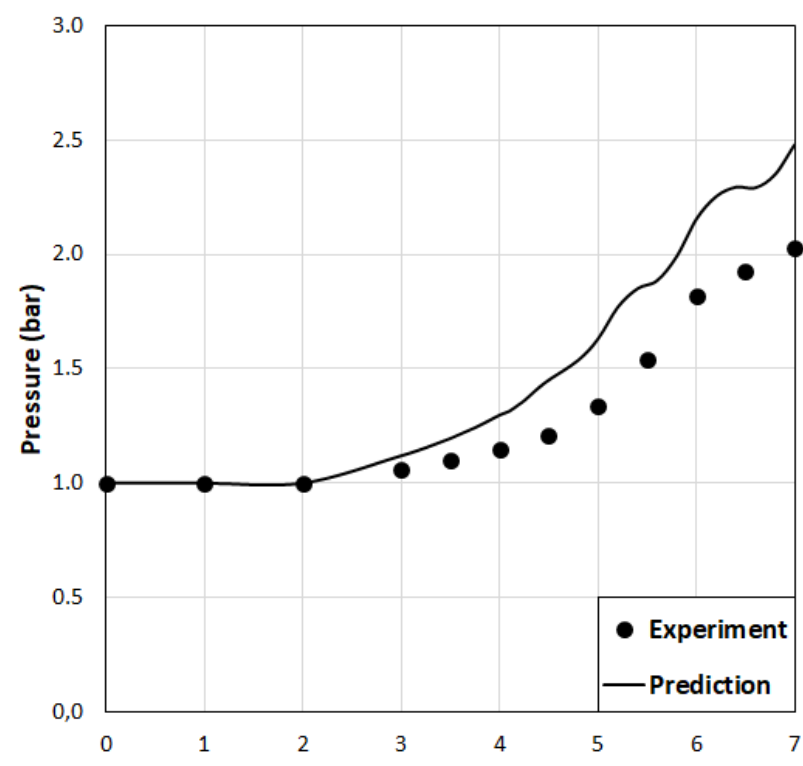

Figure 6. Pressure (absolute) dynamics as function of time, present predictions vs. experiments [15]

\section{Conclusions}

The propagation of a flame front in a homogeneous and initially quiescent hydrogen-air mixture in a channel with exit contraction is numerically analyzed by means of Computational Fluid Dynamics.

For the given configuration, the compressibility effects are important. The average pressure increases in time due to the applied exit contraction (opening ratio: 0.187 ) and pressure waves occur, which can affect the flame propagation.

Flow turbulence is modelled by the Realizable k- $\varepsilon$ model. In modelling combustion, turbulence-chemistry interactions are neglected. Predictions are compared with the measurements for evolution of the flame shape, propagation speed and pressure.

It is observed that the flame propagation speed, and the rate of pressure increase are overpredicted by the present approach. Still, a fair qualitative agreement to measurements is observed.

\section{References}

1. D.G. Ebling, A. Krumm, B. Pfeiffelmann, J. Gottschald, J. Bruchmann, A.C. Benim, M. Adam, R. Labs, R.R. Herbertz, A. Stunz, "Development of a system for thermoelectric heat recovery from stationary industrial processes", Journal of Electronic Materials, 45(7), pp.3433-3439 (2016)

2. M. Götz, J. Lefebvre, F. Mörs, A. McDaniel Koch, F. Graf, S. Bajohr, R. Reimert, Th. Kolb, "Renewable power-to-gas: a technological and economic review", Renewable Energy, 85, pp.13711390 (2016)

3. A.C. Benim, B. Epple, B. Krohmer, "Modelling of pulverised coal combustion by a Eulerian-Eulerian two-phase flow formulation", Progress in
Computational Fluid Dynamics - An International Journal, 5(6), pp.345-361 (2005)

4. S. De, A.K. Agarwal, V.S. Moholkar, B. Thallada (Eds.), Coal and Biomass Gasification, (Springer, Berlin, Germany, 2018)

5. IAEA, "Hydrogen Production Using Nuclear" Energy, IAEA Nuclear Energy Series No. NP-T-4.2, Internat. Atomic Energy Agency, Vienna (2013)

6. A.C. Benim, K.J. Syed, Flashback Mechanisms in Lean Premixed Gas Turbine Combustion, (Academic Press, Cambridge, MA, USA, 2014)

7. S.Y. Yang, S.H. Chung, H.J. Kim, "Effect of pressure on quenching meshes in transmitting hydrogen in combustion", Nuclear Engineering and Design, 224, pp.199-206 (2003)

8. S.W. Hong, J.H. Song, "Flame-quenching model of the quenching mesh for H2-Air mixtures", Journal of Nuclear Science and Technology, 50, pp.12131219 (2013)

9. Z.B. Song, L.J. Wei, Z.Z. Wu, "Effects of heat losses on flame shape and quenching of premixed flames in narrow-channels", Combustion Science and Technology, 180, pp.264-278 (2008)

10. B. Lewis, G. von Elbe, Combustion, Flames and Explosions of Gases, $3^{\text {rd }}$ ed., (Academic Press, Orlando, USA 1987)

11. H. Philips, "On the transmission of an explosion through a gap smaller than the quenching distance", Proceedings Royal Society, 7, pp.129-135 (1963)

12. Biennial report on hydrogen safety (version 1.2), European NoE HySafe, http://www.hysafe.org/BRHS (2007)

13. M.A. Green, "Hydrogen safety issues compared to safety issues with methane and propane", AIP Conference Proceedings, 823, pp.823-319 (2006)

14. H. Xiao, Q. Wang, X. He, J. Sun, L. Yao, "Experimental and numerical study on premixed hydrogen/air flame propagation in a horizontal rectangular closed duct", International Journal of Hydrogen Energy, 35, pp.1367-1376 (2010).

15. H. Xiao, D. Makarov, J. Sun, V. Molkov, "Experimental and numerical investigation of premixed flame propagation with distorted tulip shape in a closed duct", Combustion and Flame, 159, pp.1523-1538 (2012)

16. H. Xiao, Q. Wang, X. Shen, W. An, Q. Duan, J. Sun, "An experimental study of premixed hydrogen/air flame propagation in a partially open duct", International Journal of Hydrogen Energy, 39, pp.6233-6241 (2014)

17. M. Yu, X. Yang, K. Zheng, L. Zheng, W. Wen, "Experimental study of premixed syngas/air flame deflagration in a closed duct", International Journal of Hydrogen Energy, 43, pp.13676-13686 (2018)

18. X. Yang, M. Yu, Z. Zheng, S. Wan, L. Wang, "An experimental investigation into the behavior of premixed flames of hydrogen/carbon monoxide/air 
mixtures in a half-open duct", Fuel, 237, pp.619-629 (2019)

19. ANSYS® FLUENT, www.ansys.com

20. S.R. Turns, An Introduction to Combustion, $3^{\text {rd }}$ ed., (McGrawHill, New York, USA, 2012)

21. R.B. Bird, W.E. Stewart, E. N. Lightfoot, Transport Phenomena, $2^{\text {nd }}$ ed., (Wiley, NY, 2002)

22. A.C. Benim, "A finite element solution of radiative heat transfer in participating media utilizing the moment method", Computer Methods in Applied Mechanics and Engineering, 67(1), pp.1-14 (1988)

23. R.J. Kee, F.M. Rupley, J.A. Miller, "The Chemkin thermodynamic data base", Sandia Report, SAND87-8215B (1991)

24. R.A. Shevla, "Estimated viscosities and thermal conductivities of gases at high temperatures", NASA Technical Report R-132 (1962)

25. R.C. Reid, J.M. Prausnitz, B.E. Poling, The Properties of Gases and Liquids, $4^{\text {th }}$ ed., (McGrawHill, New York, USA, 1987)

26. P. Sagaut, Large Eddy Simulation for Incompressible Flows, 3rd Ed., (Springer, Berlin, 2006)

27. A.C. Benim, M.P. Escudier, A. Nahavandi, A.K. Nickson, K.J. Syed, F. Joos, "Experimental and numerical investigation of isothermal flow in an idealized swirl combustor", International Journal of Numerical Methods for Heat \& Fluid Flow, 20(3), pp.348-370 (2010)

28. A.C. Benim, S. Iqbal. W. Meier, F. Joos, A. Wiedermann, "Numerical investigation of turbulent swirling flames with validation in a gas turbine model combustor", Applied Thermal Engineering, 110, pp.202-212 (2017)

29. P. A. Durbin. B.A. Pettersson Reif, Statistical Theory and Modeling for Turbulent Flows, $2^{\text {nd }}$ Ed (Wiley, Chichester, 2011)

30. T.H. Shih, W.W. Liou, A. Shabbir. Z. Yang, J. Zhu, "A new k- $\varepsilon$ eddy-viscosity model for high Reynolds number turbulent flows - Model development and validation", Computers and Fluids, 24(3), pp.227238 (1995)

31. M.O. Conaire, H.J. Curran, J.M. Simmie, W.J. Pitz, C. K. Westbrook, "A comprehensive modeling study of hydrogen oxidation", International Journal of Chemical Kinetics, 36, pp.603-622 (2004) 